\title{
Orbital Floor Fractures: Management Protocols
}

\author{
${ }^{1}$ Hemant Chopra, ${ }^{2}$ Rajinder Mittal, ${ }^{3}$ Kapil Dua, ${ }^{4}$ Neha Chopra, ${ }^{5}$ Vikrant Mittal \\ ${ }^{1}$ Professor and Head, Department of ENT, Dayanand Medical College and Hospital, Ludhiana, Punjab, India \\ ${ }^{2}$ Associate Professor, Department of Plastic Surgery, Dayanand Medical College and Hospital, Ludhiana, Punjab, India \\ ${ }^{3}$ Associate Professor, Department of ENT, Dayanand Medical College and Hospital, Ludhiana, Punjab, India \\ ${ }^{4}$ Intern, Dayanand Medical College and Hospital, Ludhiana, Punjab, India \\ ${ }^{5}$ Senior Resident, Department of ENT, Dayanand Medical College and Hospital, Ludhiana, Punjab, India
}

Correspondence: Hemant Chopra, Professor and Head, Department of ENT, Dayanand Medical College and Hospital, Ludhiana Punjab, India

\begin{abstract}
Orbital fractures commonly occur in maxillofacial trauma causing enophthalmos and diplopia. If not properly managed the cosmetic and functional problems can virtually become untreatable. In recent years, management of these fractures has been standardized with special emphasis on methods of treatment, timing and materials used for reduction.
\end{abstract}

Keywords: Orbital floor fracture, blow out fractures, facial injuries, bone graft, silastic block.

\section{INTRODUCTION}

A true blowout fracture of the orbit can occur as a specific syndrome without any other associated facial fractures (the so-called pure blowout fracture) or it can be found in association with multiple facial injuries as is frequently the case in automobile accidents. However, isolated orbital floor fracture represents $21.4 \%$ of all the facial fractures. ${ }^{1}$ Blow out fracture of orbit was first described by Lang in early 1900's. The exact description of the fracture was first given by Converse and Smith. It was in fact Smith who first described inferior rectus entrapment in between the fractured fragments, causing decreased ocular mobility. ${ }^{2}$

The etiology of the blow out fracture of the orbit is controversial, the older "hydraulic theory" is that blow-out fractures resulted from a sudden increase in orbital pressure caused by the application of force by a nonpenetrating object that is greater in diameter than the orbital entrance. ${ }^{3}$ Following the blow, the globe is propelled posteriorly, and the orbital contents are compressed posteriorly toward the orbital apex. The 'blow out' fracture of orbit usually involves the medial wall and floor of the orbit. Anatomically, the orbital floor undergoes fracture in posteromedial part since the tubular architecture of the canal provides some mechanical strength to the floor. A more recent theory, the "buckling theory," 4 states that a blunt object strikes the inferior orbital rim, which leads to compression of the rim and direct buckling of the orbital floor. Converse, Smith, Obear, and Wood-Smith (I967), listed the automobile, the human fist, and the human elbow as the most common etiological factors in a series of 100 cases. $^{5}$ The outcome of this type of fracture depends upon proper diagnosis, timing of surgery, appropriate surgical approach and selection of suitable graft material. The basic objective of reconstruction of orbital defect is to restore orbital volume, function and esthetics.

\section{MATERIAL AND METHODS}

A series of twenty cases of traumatic orbital floor blow-out fractures who presented to Dayanand Medical College and Hospital, Ludhiana (India) with the chief complaints of diplopia and enophthalmos (Fig. 1) were taken up for this study. The diagnosis was based on history, i.e. cause of injury (Table 1), clinical presentation (Table 2), eye examination including visual acuity, perimetry and extraocular movements and radiological examination. All the patients were subjected to evaluation by ophthalmologist and plastic surgeon. X-ray paranasal sinuses was done to see the classical "tear drop sign" of prolapsed orbital contents, the fractured fragments and the presence of hemosinus. To ascertain the location and extent of the defect and to see other craniofacial injuries coronal CT scans with bony windows were done (Fig. 2). The typical physical findings usually enable one to make the diagnosis on clinical grounds. The initial physical examination may reveal only periorbital ecchymosis, but within 24 to 48 hours the other physical signs generally become manifest. Of these 20 
patients, six patients who had minimal trauma and showed no radiological evidence of entrapment or orbital floor displacement, were subjected to conservative treatment. The other 14 patients who showed radiological evidence of extensive loss of the orbital floor were reduced using different implants to reconstruct the defects as explained later. All the patients were operated by transconjunctival/ endoscopic approach through lower eyelid.

\section{OBSERVATIONS}

Most of the patients who presented with orbital floor fracture were in the age group of 18 to 45 years as this is the most susceptible age group for accidental injuries. Majority of the patients, i.e. $>75 \%$ were repaired late, i.e. after 1 month due to delayed presentation. All the six patients who were

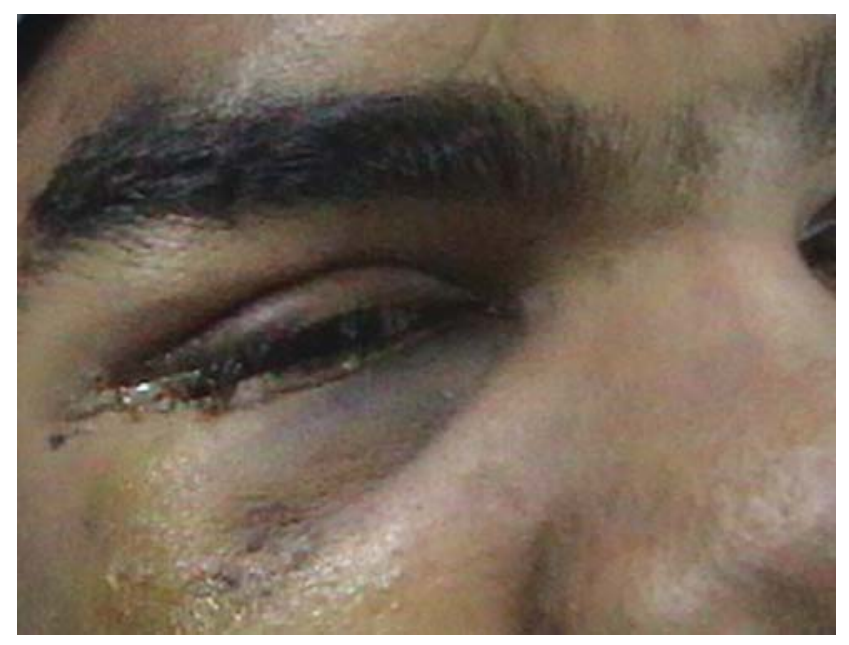

Figure 1: Clinical picture of patient with right orbital blow out fracture



Figure 2: Coronal CT scan showing right orbital floor fracture with tear drop sign

\begin{tabular}{|llll|}
\multicolumn{4}{c}{ Table 1: Cause of injury } \\
\hline & Roadside accident & Fights & Sports injuries \\
\hline No. of patients & 12 & 6 & 2 \\
\hline
\end{tabular}

Table 2: Clinical presentation

$\begin{array}{lc} & \text { No. of patients } \\ \text { Enophthalmos } & 20 \\ \text { Diplopia } & 20 \\ \text { Hypoesthesia } & 1\end{array}$

treated conservatively had good recovery. Of those 14 patients, who were treated surgically; due to small defect silastic sheet was put in endoscopically in one case, silastic block in 5 patients and bone grafts from iliac crest in eight cases by transconjuctival approach (Table 3). One patient who was treated with silastic sheet presented with sheet prolapse in maxillary sinus after 3 months with persistent enophthalmos (Fig. 3). The sheet was removed endoscopically from maxillary sinus and repair was done with bone graft from iliac crest after one year and had satisfactory result. All the patients were followed up at 2, 4 and 6 months and showed good recovery.

\section{DISCUSSION}

Early diagnosis and treatment of a blowout fracture is extremely important since the prognosis in such cases is excellent. It is therefore important that all patients, in whom a blowout fracture is suspected, should be followed carefully for several days after the initial injury. In our study, most

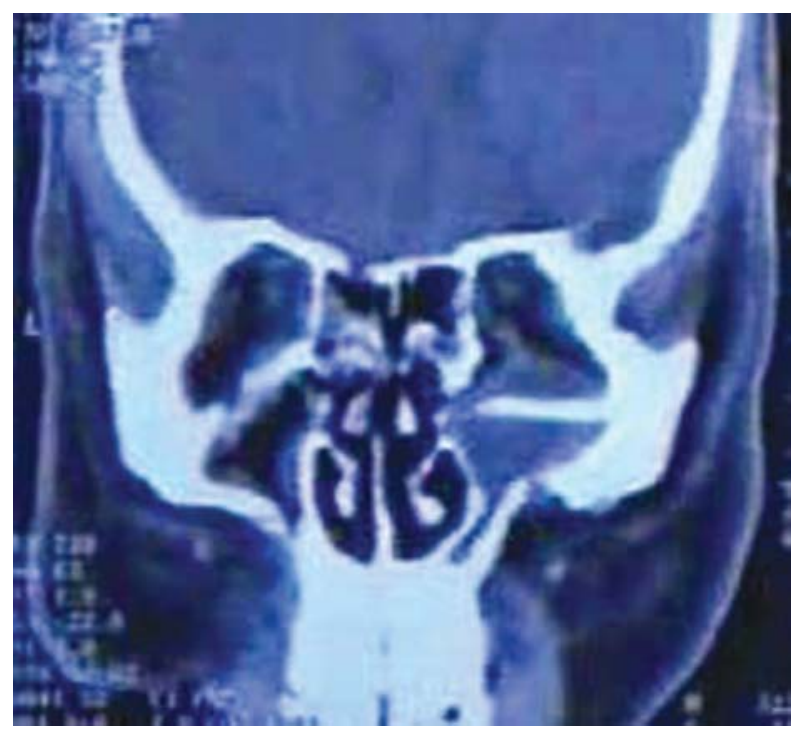

Figure 3: Coronal CT scan showing displaced silastic sheet in maxillary sinus 
Table 3: Types of grafts used

$\begin{array}{lllll}\text { Material used } & \text { No. of patients } & \text { Surgical approach } & \text { Complication } & \text { Follow-up } \\ \text { Silastic sheet } & 1 & \text { Endoscopic } & \text { Sheet prolapse } & \text { Revision with bone graft } \\ \text { Silastic block } & 5 & \text { Transconjunctival } & \text { Nil } & \text { Satisfactory } \\ \text { Iliac crest bone graft } & 8 & \text { Transconjunctival } & \text { Nil } & \text { Satisfactory }\end{array}$

of patients $(>75 \%)$ were treated around 1 month after injury due to either financial reasons or delayed referral from other departments. There is a varied opinion regarding the indication and timing for fracture repair. Some authors suggest that surgical exploration can be obviated in case of diplopia which resolves within 14 days unless extensive bony wall defect is detected. ${ }^{3}$ Another school advocates waiting period of 4 to 6 months prior to undertaking surgical exploration. ${ }^{4}$ Orbital fractures can be repaired when the edema and hemorrhage from the acute event is beginning to resolve, and waiting 7 to 10 days for repair is often appropriate. Waiting longer than 1 month often results in fibrous tissue formation, leading to contracture of the prolapsed tissue and the results are generally not satisfactory. ${ }^{6}$

In the present study, more than half of the cases of orbital floor blow-out fractures occured due to roadside accidents (Table 1). In western countries such as USA and UK, most of the orbital fractures are sustained during sports ${ }^{7}$ (especially soccer). Absolute indications for reconstruction of orbital floor are diplopia with muscle entrapment, enophthalmos and large defect. Nonresolving oculocardiac reflex, the "white-eyed" blowout fracture, and early enophthalmos or hypoglobus are indications for immediate surgical repair. Surgery within 2 weeks is recommended in cases of symptomatic diplopia with positive forced duction test and evidence of orbital soft tissue entrapment on computed tomography or large orbital floor fractures that may cause latent enophthalmos or hypo-ophthalmos. ${ }^{8}$ Banu and Randall ${ }^{9}$ have suggested surgical repair of blowout fractures within two weeks of trauma to decrease the incidence of residual diplopia.

The commonly used surgical approaches to the orbital floor are through the lower eyelid and include transconjunctival, subciliary, and through the lower third of the eyelid. In the present study transconjunctival approach was utilized as this approach provides adequate visualization and cosmetically acceptable scars. A transconjunctival incision was used, incising through the lower eyelid and retractors were applied to the inferior orbital rim. Periosteal elevators were then used to expose the orbital floor.
Unfortunately, postoperative lid malposition can occur in a small percentage of cases. Another limitation is easy visibility of the posterior orbit, which often is obscured by prolapsed orbital fat. In light of these limitations, some surgeons have begun to evaluate an endoscopic approach to orbital floor fractures. ${ }^{10-12}$ But no such limitation or complication was noted in this study. By approaching these fractures from below, without significant orbital manipulation, urgent reduction of entrapped inferior rectus muscle can be accomplished, reducing the chance of permanent dysfunction from prolonged ischemia and pressure necrosis.

In the present study, of the 14 patients, who were treated surgically silastic sheet was put in endoscopically in 1case, silastic block in 5 patients and bone grafts from iliac crest in eight cases by transconjuctival approach (Table 3). Many materials have been described for the reconstruction of orbital floor defects with varying rate of success. They include autogenic, allogenic and alloplastic material. Resorbable materials cannot be recommended for large defects. Instead, either bone or titanium must be considered to achieve a long-lasting, accurate restoration of bony orbital anatomy and dimension. ${ }^{13}$ Autogenous iliac cortical bone graft was used to repair the defect as it maintains the volume better in comparison to the cancellous bone. The goals of reconstruction in orbital blow-out fractures are to restore floor continuity, provide support of orbital contents, and prevent fibrosis of soft tissues. Although ease of use has popularized alloplasts, autogenous material provides greater biocompatibility and results in low rates of infection, extrusion, and migration. Nasoseptal cartilage has also been utilized by Amy Lai et al ${ }^{14}$ for reconstruction of orbital blowout fractures as it is an easily accessible, abundant, autogenous source with minimal donor site morbidity. ${ }^{14}$

The outcome of surgery with Silastic block was satisfactory. No postoperative complications were seen except for prolapse of silastic sheet in a case reconstructed endoscopically which was later repaired with bone graft. Although some authors have described successful results with silastic sheet implant ${ }^{11,12}$ but in our study we got best results with iliac crest bone grafts. 


\section{CONCLUSION}

All the patients treated with iliac crest bone grafts with concave side upwards had excellent results as it fits snugly in the defect. Therefore bone graft proved to be the best reconstructive material in orbital floor blowout fractures with no complications such as extrusion, foreign body reaction or infection.

\section{REFERENCES}

1. Seberer M, Sullivan WG, Smith DJ Jr. An analysis of 1423 Facial fractures in 788 patients at an urban trauma center. J Trauma 1989;29:388.

2. Sidney Lerman. Blowout fracture of the orbit. Brit J Ophthal I 970;54:90.

3. Emery JM, Van Noorden GK, Schlernitzaver DA. Management of orbital floor fracture. Am J Ophthalmol 1972;74:299-306.

4. Courtney DJ, Thomas S. Isolated orbital blow out fractures: Survey and review. Br J of Oral and Maxillofac Surg 2000; 496-502.

5. Converse JM, Smith B, Obear MF, Smith W. Orbital blow out fracture. A ten years survey. Plast Reconstr Surg 1967;39:20-25.
6. Gruss JS. Complex nasoethmoid-orbital and midfacial fractures: Role of craniofacial surgical techniques and immediate bone grafting. Ann Plast Surg 1986;17:377.

7. Jones NP. Orbital blow-out fractures in sport. Br J Sports Med 1994;28:272-75.

8. Michael A. Burnstine. Clinical recommendations for repair of isolated orbital floor fractures: An evidence-based analysis, Ophthalmology Volume 109, Issue 7, July 2002;1207-10.

9. Banu M. Hossal, Randall L. Beatty. Diplopia and enophthalmos after surgical repair of blowout fracture. Orbit 2002;21(1): 27-33.

10. Smith B, Regan WF. Blow-out fractures of the orbit. Mechanism and correction of internal orbital fracture. Am J Ophthalmol 1957;44:733.

11. Farwell DG. Endoscopic repair of orbital floor fractures. Facial Plast Surg Clin North Am 2006;14(1):11-16.

12. Strong EB, Kim KK, Diaz RC, et al. Endoscopic approach to orbital blowout fracture repair. Otolaryngol Head Neck Surg 2004;131(5):683-95.

13. Kontio R. Management of orbital fractures. Oral Maxillofac Surg Clin North Am 21(2):209-20.

14. Amy Lai, Richard E Gliklich, Peter AD Rubin. Repair of Orbital Blow-out Fractures With Nasoseptal Cartilage. The Laryngoscope Volume 108(5):645-50. 